\title{
PRINCIPLES OF LIGHTWEIGHT STRUCTURES IN THE SCULPTURAL CONCEPTIONS OF NAUM GABO
}

Theresa Neurohr

University of Oxford; History of Art and Visual Culture

Damiano Pasini

McGill University; Department of Mechanical Engineering

\section{INTRODUCTION}

They tend to look at a work of mine as an object which can be taken in at a single glance; perhaps it's because they know it only from photographs which make it look like an object, a flat image. In reality it is a continually unfolding manipulation of space which must be read as an experience in time [...] This is why the placing of my works in an exhibition is so vital. In American exhibitions I've sometimes found them placed against the wall, as if they were reliefs. This kills half the life the sculpture has for the spectator; I don't want him just to come up and stand in front of it, but to walk around it, look through it, up at it, down at it. In other words, in 'reading' the space, to forget his customary terrestrial movements and restrictions and become as they are - weightless (Our Art Critic 2000, 242). (Naum Gabo on his work and its spectators)

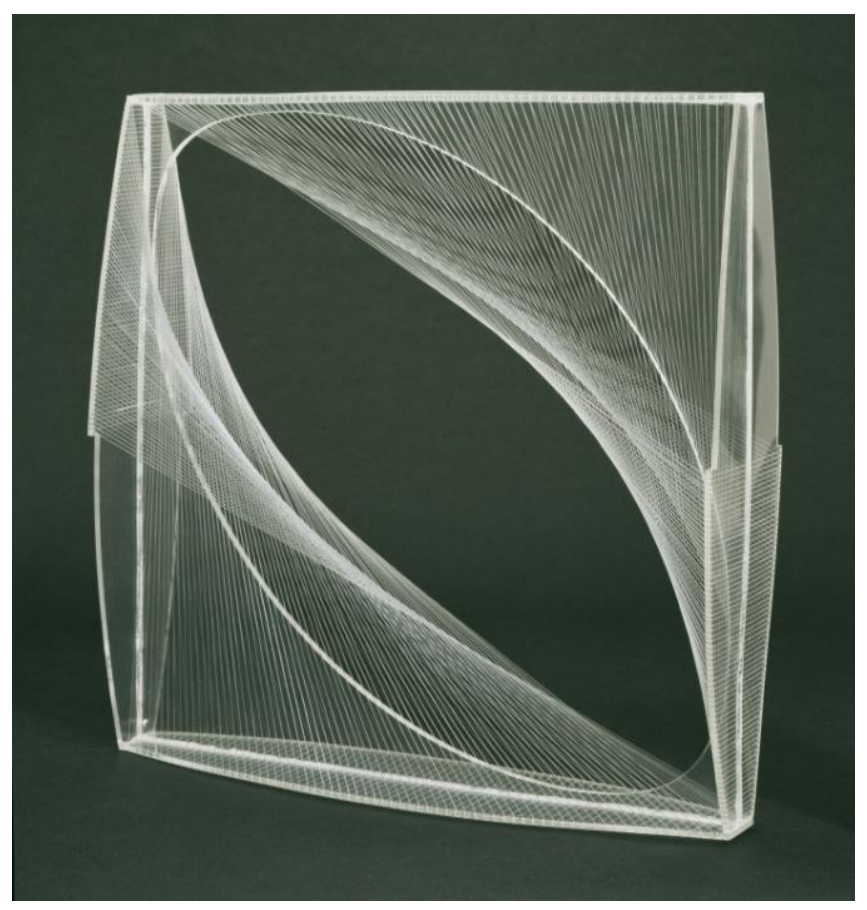

Figure 1: Naum Gabo, Linear Construction in Space No.1, Variation, 1942-3, acrylic and nylon, 34.9 x $34.9 \mathrm{~cm}$. (C) Tate, London 2008. The works of Naum Gabo (C) Nina Williams. 
These words by the $20^{\text {th }}$ century artist Naum Gabo highlight that picturing his works in a publication might not provide the ideal experience that the sculptures might offer when properly displayed. Consolation lies in the fact that it is possible to envisage what resides at the heart of Gabo's sculptures, namely an experience of “weightlessness” in space. The exactness of Gabo's constructions conveys an essence of lightness, balance and equilibrium (Figure 1). These principles reverberate with concepts of optimum structures, in which minimum-weight design is achieved through removal of redundant elements that do not contribute to balance external loads and resist internal forces. This concept is further consistent with prevailing aspirations at the beginning of the $20^{\text {th }}$ century for economy of material and formal simplification, together with tendencies to lightweight and transparent design.

This paper elaborates on the aesthetic and structural affinities Gabo's sculptures bear with these notions, highlighting how these informed his sculptural conceptions. An investigation of Gabo's constructive technique demonstrates how his spatial conceptions, method of construction and use of material developed towards a sculptural expression of lightness. Characterised by precision, this technique enabled Gabo to convey an aesthetic that would be appropriate for a modern, industrial society. The aim here is to offer a new way of looking at Gabo's sculptural aesthetic by identifying analogies with theoretical formulations of minimum weight frame-structures, as encountered in the theory of the engineer/scientist A.G.M. Michell. This approach is meant to demonstrate how Gabo's sculptures are governed by principles of optimum design and therefore convey an essence of lightness, equilibrium, and balance.

Further, concepts of material economy in nature are discussed. Particular attention is drawn to ideas of an organic aesthetic promoted through the art critic Herbert Read, and concepts of optimum design in nature as explored in the work of the biologist D'Arcy Thompson, in order to investigate how biological concepts of optimum patterns and structures supported Gabo's sculptural development. Concepts of a lightweight sculptural expression are above-all consistent with the historical context within which Gabo worked. This research thus investigates various contextually-grounded sources that informed Gabo on concepts of optimum design and enabled him to develop a sculptural expression of lightness. 


\section{HISTORICAL CONTEXT}

Naum Gabo was born in Russia in 1890 (Hammer and Lodder 1987, 2000a), (Nash 1985). He studied natural sciences and engineering in Munich and subsequently lived for various periods in Germany, Norway, Paris, England, and America, where he died in 1977. Throughout his career, Gabo circulated within environments of significant artistic and architectural development, which provided stimulation and fruitful intellectual debate with artists, architects, and art critics about the forging of new artistic forms. Certain $20^{\text {th }}$-century notions provide a background in which Gabo's sculptural language developed so that it could manifest concepts of lightness and efficiency. The Industrial Revolution had witnessed immense technological changes and social transformations (Colquhoun 2002, 9-11), (Curtis 1996), (Frampton 1992). Rapid changes could be observed through new material usage, technologies and revolutionary innovations in science. Machines were developed to make production both cheaper and more efficient. Architects, engineers, and artists responded variously to these developments to ultimately propose a new style which would be suitable to the aspirations of a modern, industrial society.

Concepts of efficiency were exhibited in a predominance of avant-garde $20^{\text {th }}$-century architecture through characteristics of transparency, spatial openness, and lightness, as highlighted by the rise of skeletal constructions built from industrial materials, such as iron and steel (Curtis 1996, 38), (Hammer and Lodder 2000a, 141-6). Structural concepts of lightweight construction were eagerly pursued and developments in reinforced concrete design, such as modern shell construction, offered significant innovations towards lightweight design. Geometry is a crucial aspect in considering structural lightweight properties (Engel 1968). The mass efficiency of long-span structures can be improved through an arrangement in which the longitudinal axes of constituent members follow the direction of applied forces. Based on this structural criterion, Heinrich Engel highlighted that members whose overall configuration aligns with a natural flow of stresses generate only axial forces, without bending (Pasini 2003, 6-7), (Pasini et al. 2006). This results in efficient material use. In 1917, the engineer Eugéne Freyssinet in France, for example, designed reinforced concrete airship hangars at Orly. These were constructed of arched sections, capable of spanning $80 \mathrm{~m}$ (Curtis 1996, 44) and demonstrate a structure in which the overall shape approaches a system which follows the natural path of internal stress flow, termed 
the catenary curve, thus transmitting external forces efficiently by simple axial stresses. The catenary curve is formed when a loop of chain (a catena) is suspended from two points.

\section{FOUNDATIONS OF GABO'S CONSTRUCTIVE IDEAS}

Gabo expressed continuous interest in architecture and engineering, which was fostered and informed through close contact with contemporary architects. He would thus have certainly been familiar with $19^{\text {th }}$ and $20^{\text {th }}$ century constructions which pursued lightweight structural principles and would have encountered prevailing tendencies of rationalist thinking, which proposed that new forms were rooted in structural demands from which aesthetic forms emerged naturally by way of formal reduction (Curtis 1996, 37-47). In 1931 Gabo presented a complete design for the Palace of Soviets competition in Moscow, which reveals his comprehension of structural design principles and weight-reduction design (Gabo 1931). Sensitivity to such structural principles certainly provided sculptural possibilities.

\section{Constructive Art and Gabo's Sculptural Techniques}

Revolutionary Russia motivated artists to develop artistic expressions in conformity with new social ideals. In 1920, Gabo co-published The Realistic Manifesto with his brother, Antoine Pevsner, in which he delineated the foundations of a new concept of constructive art (Gabo and Pevsner 1920). An essential technique of Gabo's earlier figurative constructions consisted of assembling planar elements made of cardboard, wood and later also metal to define spatial boundaries. Gabo's sculptural conceptions in terms of spatial volumes as opposed to mass can be understood as the foundation of a lightweight sculptural expression.

Inspired by Russian avant-garde artists, Cubism, and geometric models, Gabo's oeuvre increasingly adopted a style of abstract purity (Hammer and Lodder 2000a, 43, 2000b, 5-18). This formal reduction exhibits a propensity to remove redundant material. Later adoption of transparent materials further heightened the sensation of lightness in visual terms. The organic formal aesthetic Gabo witnessed in Britain manifests in his work through an increasingly curvilinear quality. 
With respect to the lightweight aesthetic of Gabo's sculptures, the adoption of curvilinear forms is particularly significant, since these members can follow an internal stress path, as previously discussed, thus facilitating material efficiency. In visual terms, curvilinearity allowed Gabo to define spatial boundaries with less material. Furthermore, the transparency and malleability of the plastic, Perspex, provided significant opportunities for a lightweight spatial conception. Other sculptures were characterised by sets of incised lines to define internal contours and describe complex spaces, as for example Gabo's Construction in Space: Crystal, displayed in Figure 2.

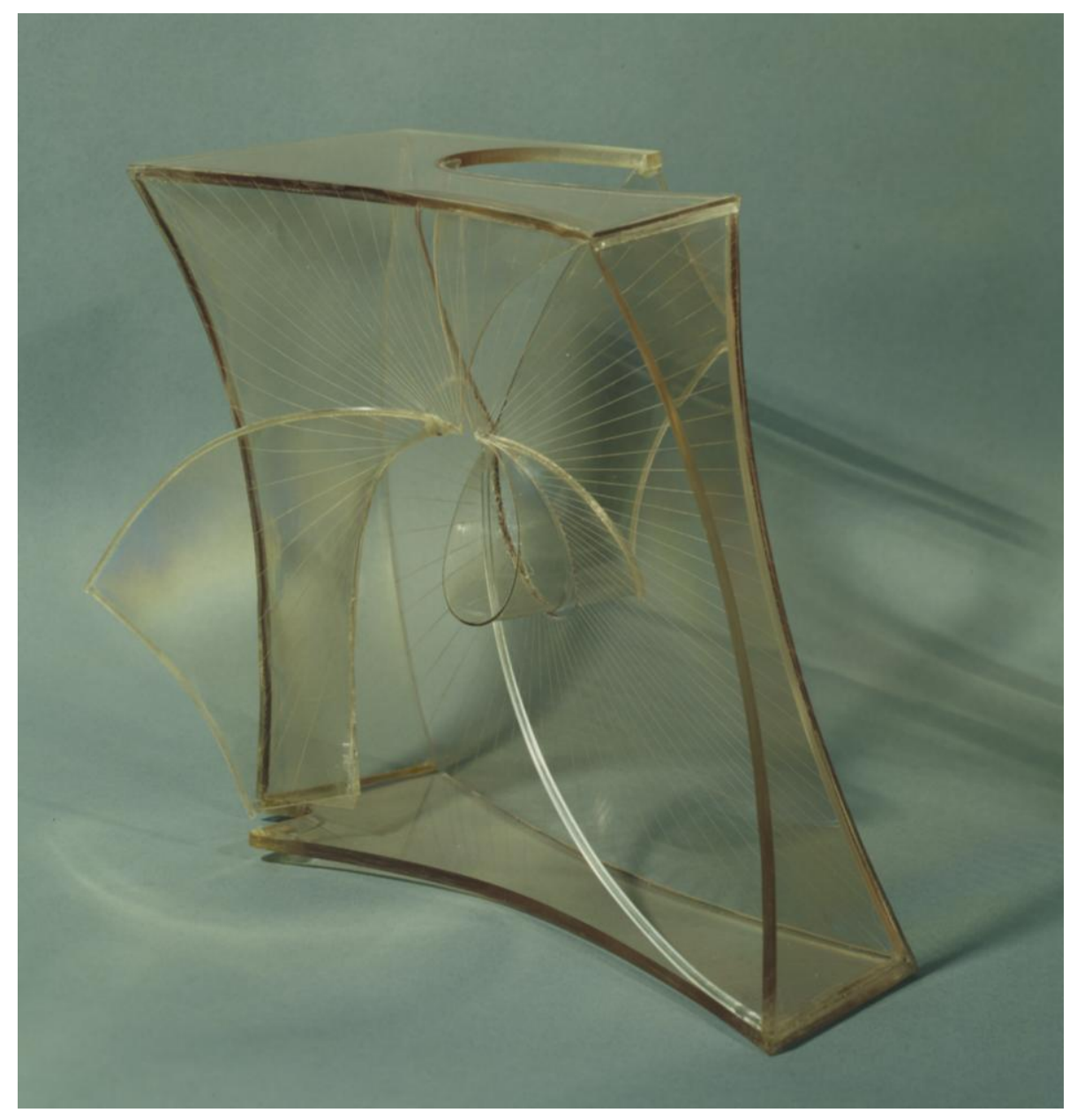

Figure 2: Naum Gabo, Construction in Space: Crystal, 1937, rhodoid [and celluloid], 22.9 x 27.3 x 20.3 $\mathrm{cm}$. Courtesy Annely Juda Fine Art, London. The works of Naum Gabo (C) Nina Williams.

Even though this technique of incision did not physically enhance lightweight properties, visually it increased a sensation of exactness. However, when the incisions were replaced by 
physical strings, they can be seen to possess structural implications. Gabo's sculptures were now partially constructed of lightweight tensile members, such as nylon and metal wires, for further weight-reduction (Figure 1).

Gabo's sculptural oeuvre reverberates with contemporary architecture, which highlights his implementation of widespread structural principles. The constructive method provided a means of communicating an aesthetic of precision, appropriate to Gabo's historical context. Gabo asserted: "We affirm the line only as a direction of the static forces and their rhythm in objects" (Gabo and Pevsner 1920, 151-2). This concisely indicates his structural conceptions such that his sculptures are conceived of as a constitutive system of equilibrated forces. The tensile strings which are skilfully balanced by compressive members resonate with this concept.

\section{PRINCIPLES OF OPTIMUM STRUCTURES}

Gabo's sculptures often convey a sense of balance, equilibrium and lightness, which recalls concepts of optimum structures. By looking at the theoretical formulations of least-weight framework design, the aim here is to offer a new way of looking at Gabo's sculptures which is consistent with what was the prevailing emphasis on structural concerns, formal simplification and efficiency. Concepts of optimum structures, where all redundancies have been removed, provide the epitome of these ideas. In 1904 A.G.M. Michell published a seminal work, in which he formulated design principles for minimum-weight frameworks (Michell 1904). Michell established the arrangement of structural frame members within a space in order for a minimum quantity of material to sustain a given load. The minimum-weight design of a frame structure is such that external loads are balanced by a system of internal axial forces that are withstood by the struts and the ties of the framework. Michell determined that the optimal arrangement of such a framework consists of members that form a system of orthogonal (perpendicular) and tangential curves. Three geometric concepts are further defined to clarify his ideas: the involute, envelope, and evolute of a curve.

The involute is defined as any curve orthogonal to all the tangents of a given curve (Lockwood 1961), (Yates 1952). Figure 3, for example, depicts the involute of a circle, which is a 
"logarithmic" or "equiangular" spiral. Physically, the involute can be obtained by aligning a string to a given curve. It results from the path of a point of a string, which is unwound while kept taut. Figure 3 illustrates that the outer end of the string is orthogonal to the involute, while the interior end is tangent to the original curve (circle). Similarly, the involute can be derived for other geometric shapes.

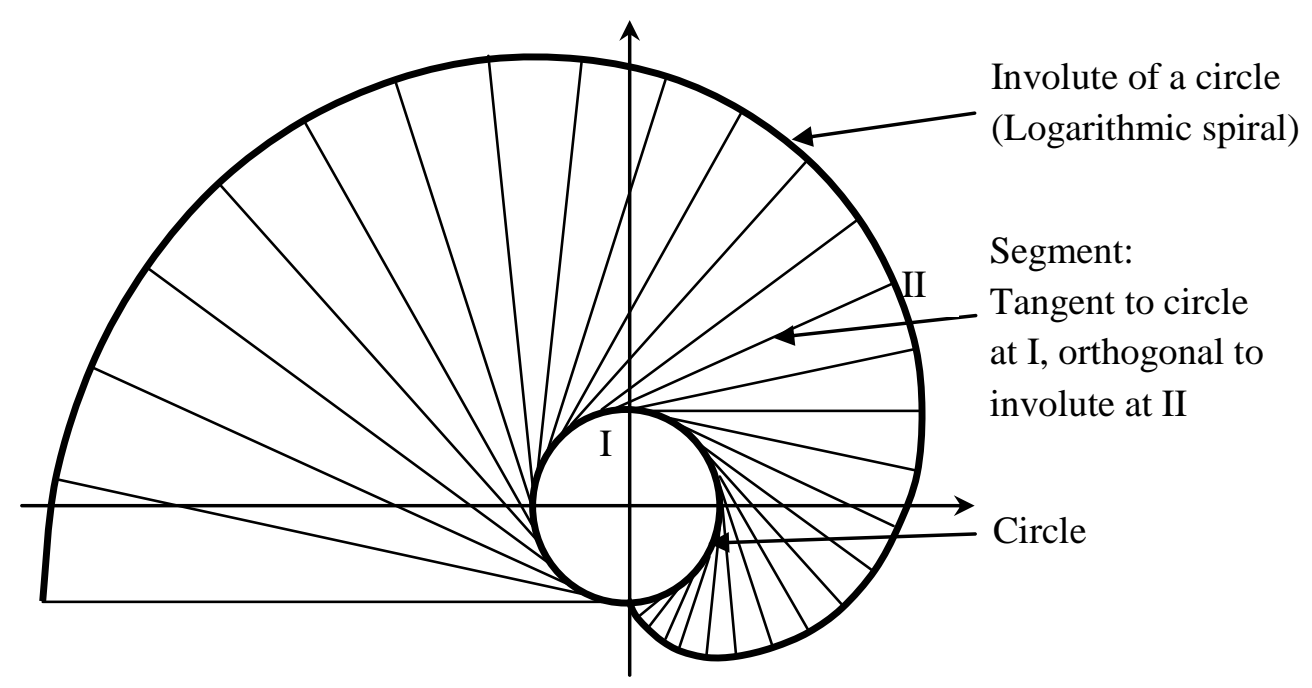

Figure 3: Involute of a circle

The envelope is defined as the curve which is tangent to a family of lines or curves (Figure 4).

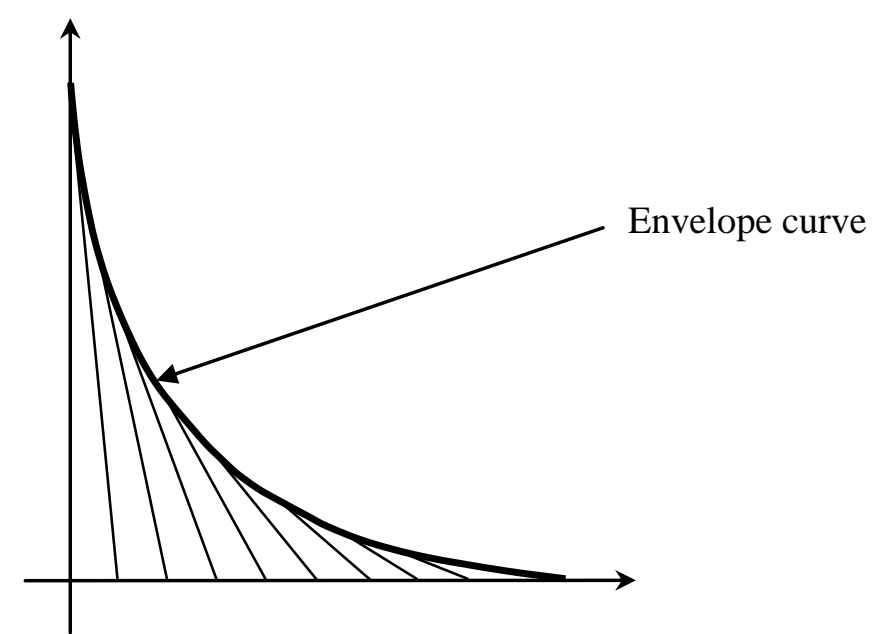

Figure 4: Envelope of a family of curves 
The evolute is the envelope of the orthogonal lines to a given curve. In Figure 5 the evolute of the ellipse is depicted as an asteroid, which is the envelope to a set of lines orthogonal to the ellipses.

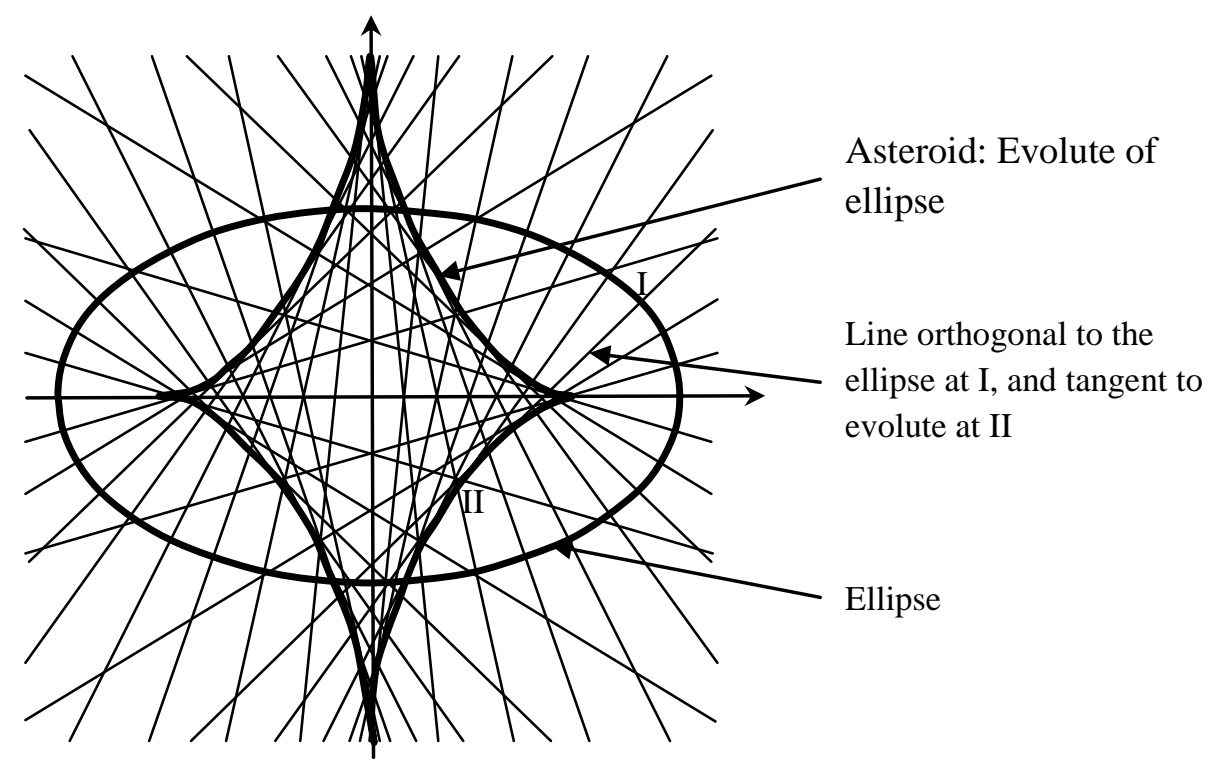

Figure 5: Evolute of an ellipse.

Michell determined that minimum-weight frameworks consist of members that satisfy conditions of orthogonality such that a system of tangents and involutes are derived from any evolute curve. Frameworks whose members follow the trajectories of these orthogonal curves and system of tangents form a least-weight structure. Their member-arrangement depends on load and boundary conditions. Michell derived curves for a simply supported beam loaded at mid-span (Figure 6). The required conditions of orthogonality for this structure can be identified by the system of involute curves seen as concentric circles with radii converging to the centre point of load application. The arrangement of the optimum structure coincides with these curves, where compressive members correspond to the system of concentric circles, and tensile members with the system of orthogonal radii-lines. 


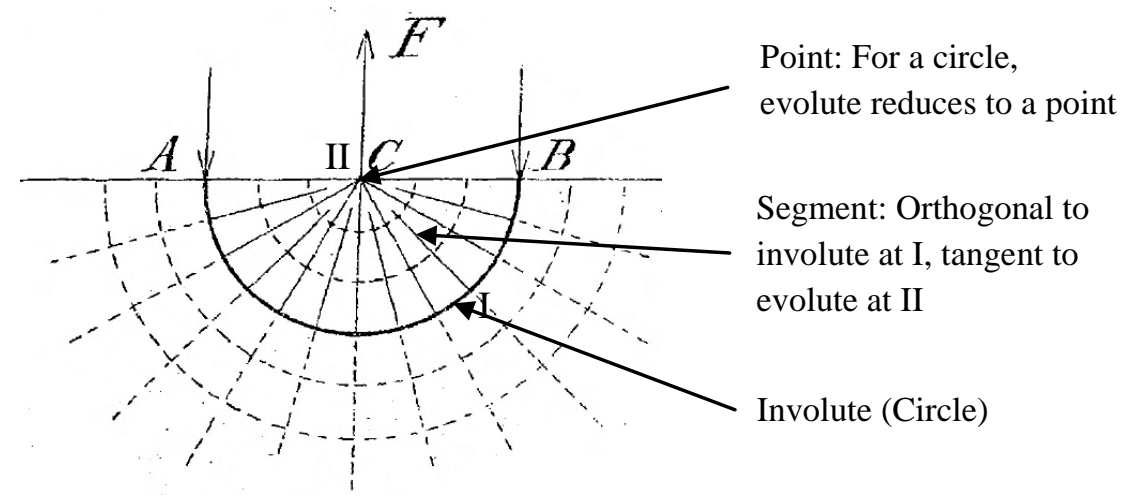

Figure 6: Lightweight frame for a simply supported beam loaded at mid-span; from A.G.M Michell, 'The Limits of Economy of Material in Frame-structures', Philosophical Magazine, 8 (1904), fig. 3.

Michell applied these principles for different load and support conditions to determine corresponding least-weight frames. The minimum weight frame for a point load applied to the end of a cantilever beam coincides with a system of tension members of equiangular spirals which are balanced by intersecting orthogonal compression members of equiangular spirals (Figure 7), where the equiangular spiral is the involute curve for a circle, specified in Figure 3.

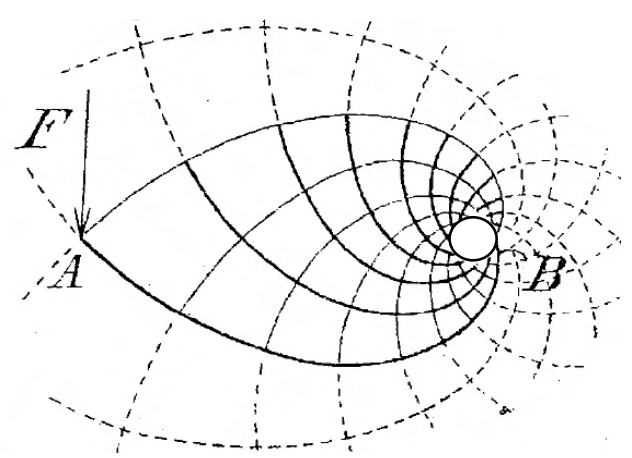

Figure 7: Lightweight frame for a cantilever beam; from A.G.M Michell, 'The Limits of Economy of Material in Frame-structures', Philosophical Magazine, 8 (1904), fig. 1.

Further, Michell applied these principles to a system whose load conditions consist of equal and opposite rotational loads applied on a central axis. The resulting minimum-weight frame consists of systems of orthogonals which coincide with lines on a sphere (Figure 8). 


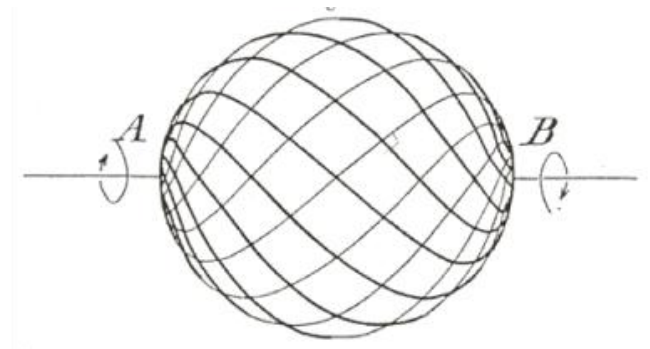

Figure 8: Lightweight frame for equal and opposite rotational loads; from A.G.M Michell, 'The Limits of Economy of Material in Frame-structures', Philosophical Magazine, 8 (1904), fig. 5.

In summary, Michell demonstrated that minimum-weight structures can be obtained through an arrangement of frame members, which coincide with uniform stress flows. These stress distributions develop within a structure as a result of external load and boundary conditions. Michell determined that uniform stress distributions follow geometric arrangements of involutes and evolutes, which are essentially curve systems of orthogonals and tangents.

\section{Principles of Optimum Structures in Gabo's Sculptures}

Bearing in mind these concepts enables to identify how such principles of least-weight frameworks are generated in Gabo's sculptures. The Perspex semicircular arches and system of nylon strings of Gabo's Linear Construction in Space No. 2, Variation (Figure 9) visually resemble Michell's structure for a simply supported beam, loaded at mid-span (Figure 6, 9). Further, Gabo's sculpture is assembled in such a way that the centre supports its perpendicular planes, thus physically providing a point load similar to Michell's structure. The Perspex planes thus resemble a compressive frame which is balanced by systems of orthogonal tensile members, such as the nylon strings, analogous to Michell's structure. Gabo's sculpture therefore not only corresponds to Michell's optimum structure in visual terms but his sculptural language also evokes its structural function. 

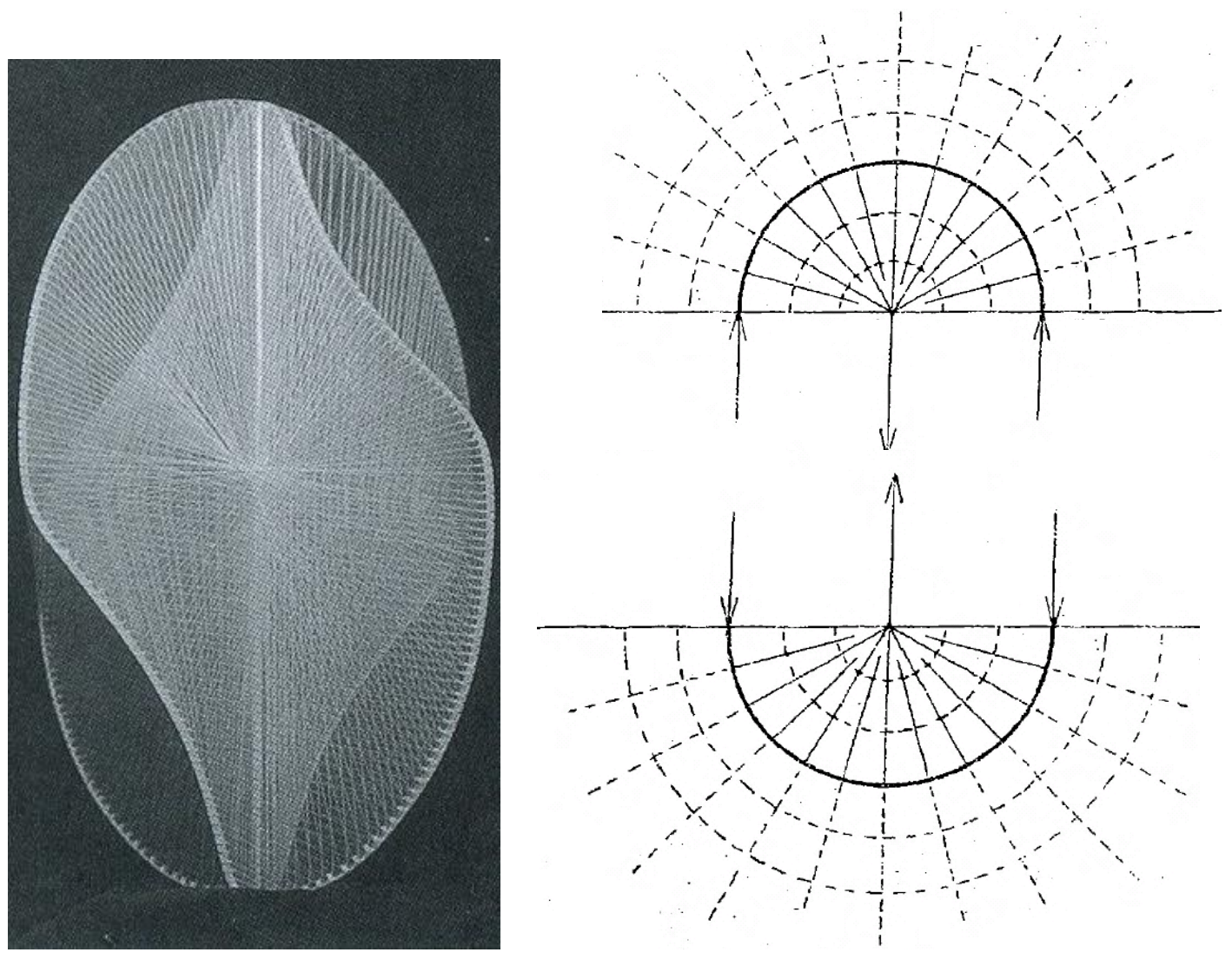

Figure 9: Analogy between Gabo's Construction in Space No. 2 (Variation) and Michell's optimum structure for simply supported beam. Naum Gabo, Construction in Space No. 2 (Variation), 1953, perspex with nylon, $22.1 \mathrm{~cm}$. Private Collection. The works of Naum Gabo (C Nina Williams. A.G.M Michell,

'The Limits of Economy of Material in Frame-structures', Philosophical Magazine, 8 (1904), fig. 3.

If we look for a parallel with Michell's spherical structure (Figure 8), Gabo's Torsion, Variation (Figure 10) provides an obvious reference. Not only the title suggests similar load conditions, but the steel spring-wires also define the sculptural space within the phosphor-bronze skeletal structure and evoke the spherical stress distribution of an equivalent lightweight framework. The curves which have been cut into the metal planes further emphasize this sense of rotational movement. 


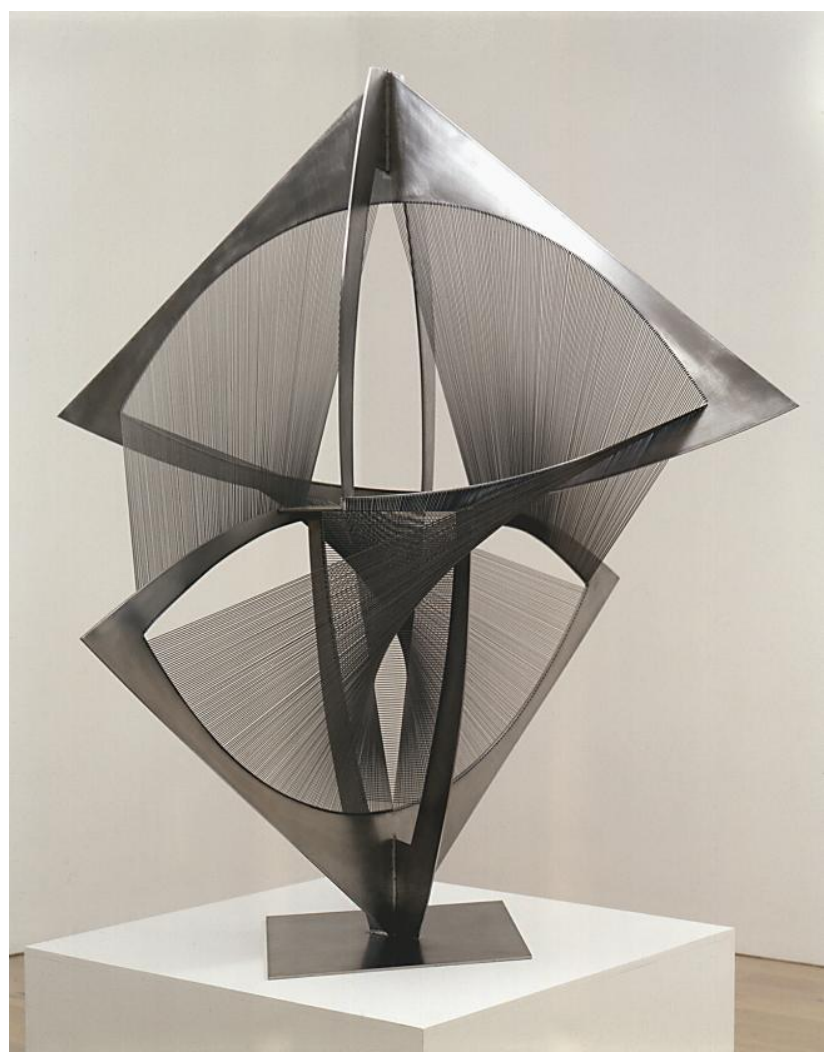

Figure 10: Naum Gabo, Torsion, Variation, c.1974/75, $136.5 \mathrm{~cm}$, stainless steel with stainless steel spring wire. Courtesy Annely Juda Fine Art, London. The works of Naum Gabo (C) Nina Williams.

Gabo later employed a similar conception for a public kinetic fountain project, the Revolving Torsion: Fountain of 1972-3. The sculpture revolves about its centre and induces rotational forces as indicated in Michell's spherical structure. Gabo intended a series of water jets to serve a similar conception to the use of strings: "Now these water jets should replace lines" (Thompson, David 2000, 276). He further explained that the revolving framework has been constructed to cause the water jets to form "a ball of water" (Thompson, David 2000, 278). The water jets thus literally represent a 'flow of stresses' analogous to Michell's conception of stress distribution. The intangibility of water jets can furthermore be interpreted as an aim to dematerialize his sculpture, moving beyond literal structure. 
Casting the net beyond the particular loading cases Michell addressed, one can identify how Gabo's sculptures generate systems of orthogonal and tangent curves similarly to systems of involutes derived from evolute curves. The Perspex frame of Gabo's Linear Construction in Space No. 1, Variation (Figure 1), for example, appears to be in perfect equilibrium with tensile strings, which define the interior space through systems of orthogonal and tangent curves. While Gabo's sculptures often consist of more complex representations beyond the loading conditions Michell derived, the aesthetic language Gabo employed certainly conveys this essence of balance, equilibrium, and lightness precisely because it embodies principles of lightweight frameworks.

\section{Inspiration from Natural Structures}

Inspiration from natural forms and structures has further importance for the consideration of concepts of optimum structures in the sculptural conceptions of Gabo. Nature exhibits a plethora of optimum structures and forms because of its propensity to minimise energy and biological matter. Gabo closely associated with the art critic, Herbert Read, who was highly interested in structural similarities between nature and science and advocated an aesthetic of organic forms (Read 1942a, 1942b, 1966). Further, Gabo was inspired by D'Arcy Wentworth Thompson's On Growth and Form (Kemp 1996, 2006, 200-38), (Hammer and Lodder 2000a, 379-401). In On Growth and Form, first published in 1917, the biologist D'Arcy Thompson investigated numerous patterns of growth and form and was interested particularly in their efficiency and optimum design (Thompson, D’Arcy 1917), (Gould 1961, 1971). He was intrigued, for example, by an engineer who immediately understood the mechanical structure of the femur (hip bone) through visual comparison to his crane design (Figure 11) (Thompson, D'Arcy 1917, 682-3). The engineer recognized that the arrangement of cancellous bone tissue resembled a diagram of tensile and compressive forces for similar loading conditions and "that Nature was strengthening 
the bone in precisely the manner and direction in which strength was required" (Thompson, D’Arcy 1917, 682).

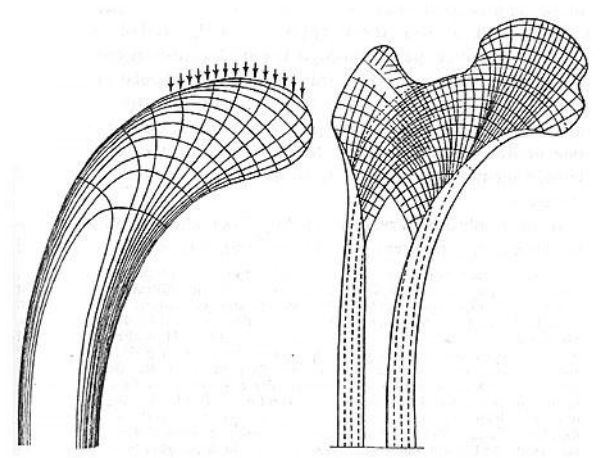

Figure 11: Comparison between stress distribution of crane design and cancellous tissue of the femur; from D'Arcy Thompson, On Growth and Form (Cambridge: Cambridge University Press, 1917), p. 681.

The engineer had essentially identified that the bone structure had been optimised through adaptive growth, which indicates that biological structures grow material to reinforce highlystressed regions in order to achieve a uniform stress distribution within the structure (Mattheck and Tesari 2004), (Pasini and Burgess 2004), (Pasini 2007). Michell's theory resorts to this principle, where frame-members align with uniform stress distributions. Even though biological structures are often subjected to complex loading patterns, nature reveals numerous examples in which patterns of optimum design principles correspond to those observed in Michell's structures (Figure 7). Thompson not only devoted sections of On Growth and Form to explore the formation of the equiangular spiral, but interestingly, he had observed the system of orthogonal curves, similarly to those of Michell's minimum-weight frames, which is exhibited in the distribution of the cancellous bone tissue (Thompson, D’Arcy 1917, 681-2). Thompson further lauded the femur for its beautiful manifestation of optimum design principles. The significant link between engineered optimum structures, natural structures, and Gabo's sculptures then is that their physical nature tends to a minimisation of material usage. As a result, the perfection, precision and exactness of these structures often convey an aesthetic of lightness, balance, and equilibrium. 


\section{Spatial Geometries: An Aesthetic Language of Precision}

While we cannot demonstrate that Gabo directly encountered Michell's theory, he was wellinformed about structural engineering concepts, and he would on his own account have observed patterns similar to stress distributions of least-weight frames in geometric models. Gabo's interest in and affinity for such models has been discussed (Hammer and Lodder 2000a, 379402), (Corrada 1992). Beyond the visual analogy Gabo's sculptures bear with mathematical string models, a significant aspect of these models lies in the fact that they often delineate surfaces by systems of tangent and orthogonal strings. These geometries illustrate precisely the behaviour of tangential curves converging unto a curve, as discussed in Michell's theory on optimum structures. While Gabo most certainly did not conceive of them as such, it is likely that such geometric representations appealed to him aesthetically and provided a visual language that corresponds to the concepts of lightweight design which Gabo aimed to convey through his constructions. This is apparent from his incising technique to evoke such patterns, which was later replaced with physical strings. The stringing method reveals Gabo's fascination with geometric representations not only in visual terms but also in terms of structural possibilities. For a sculptor with developed structural concerns this would have been highly appealing.

While Gabo demonstrated obvious structural understanding, his sculptural aim was not to precisely reproduce scientific concepts. Rather, scientific principles provided a source of inspiration and an aesthetic paradigm. Patterns he encountered in geometric representations provided a visual language of exactness. An understanding of fundamental structural principles thus allowed Gabo to perceive how such representations provided structural possibilities and a unique aesthetic. 


\section{CONCLUSION}

Gabo's social, cultural and political circumstances emphasized concerns over progress and efficiency. His upbringing and educational background provided a valuable intellectual foundation and theoretical framework for his artistic conceptions. Ensuing residence in diverse places of rich artistic and architectural developments further informed his artistic ideas. Gabo benefitted from close association with leading contemporary architects and his oeuvre clearly demonstrates shared aesthetic and structural concerns with contemporary architecture and engineering.

Gabo further encountered numerous sources where principles of optimum design, by virtue of a biologically-inspired design, informed his sculptural aesthetic. Herbert Read explicitly linked structures of science, nature and art and fervently promoted the idea that natural structures provide aesthetic value through their order and structure. D'Arcy Thompson further explored nature's perfection and his enthusiasm for biological optimum design principles certainly affected the work of Gabo.

The aim of this research was to provide a new way of looking at Gabo's sculptures via a theoretical formulation of optimum structures. This approach is not only consistent with Gabo's historical context but further helps us to understand how principles of lightweight structures are generated in his constructions. Patterns of uniform stress flow were demonstrated analytically at the beginning of the $20^{\text {th }}$ century by Michell's theory in which fundamental principles of lightweight frameworks were formulated. These principles reveal that the arrangement of lightweight frame-members is governed by geometric relations. The system of orthogonal and tangent curves that this necessitates follows beautiful patterns and Gabo's sculptures often exhibit precisely these optimum design principles.

Through the constructive technique Gabo aligned his works with contemporary theoretical and practical scientific developments. Through precision of forms, exact arrangement, and astute choice of materials Gabo developed a sculptural language that conveys an essence of lightness, equilibrium, and balance precisely because his sculptures demonstrate visual as well as structural affinities with lightweight frameworks. 


\section{ACKNOWLEDGEMENTS}

The authors wish to thank Professor Martin Kemp from the University of Oxford for the insightful discussions and valuable comments. The authors want to acknowledge that the works of Naum Gabo are the copyright of Nina Williams and further wish to thank her for her helpfulness. Furthermore, the authors are grateful for the help of Professor Martin Hammer, the Tate Gallery, and Annely Juda Fine Art in obtaining images. 


\section{BIBLIOGRAPHY}

Colquhoun, Alan. 2002. Modern Architecture. Oxford, New York: Oxford University Press.

Corrada, Manuel. 1992. On Some Vistas Disclosed by Mathematics to the Russian Avant-Garde: Geometry, El Lissitzky and Gabo, Leonardo 25, no. 3/4, Visual Mathematics: Special Double Issue: $377-84$.

Curtis, William. 1996. Modern Architecture Since 1900, 3rd ed., 8-47, 75-90, 104-117, 132-143. London: Phaidon.

Engel, Heinrich. 1968. Form-active Structures. In Tragsysteme/Structure System, 25-6. London: Iliffe.

Frampton, Kenneth. 1992. Modern Architecture: A Critical History, 3rd ed., 8-40. London: Thames \& Hudson World of Art.

Gabo, Naum. 1931. Explanatory Note to the Palace of Soviets Project Submitted Under the Motto AZ. In Gabo on Gabo: Texts and Interviews. ed Martin Hammer and Christina Lodder, 71-81. Sussex: Artists Bookworks, 2000.

Gabo, Naum, and Antoine Pevsner. 1920. The Realistic Manifesto. In Gabo: Constructions, Sculpture, Paintings, Drawings, Engravings, 151-2. London: Lund Humphries, 1957.

Gould, Stephen. 1961. Foreword. In On Growth and Form, ed. John Tyler Bonner, abridged version, vii-xiv. Cambridge: Cambridge University Press.

Gould, Stephen. 1971. D'Arcy Thompson and the Science of Form, New Literary History 2, no. 2: 229-58.

Hammer, Martin, and Christina Lodder. 1987. Naum Gabo and the Constructive Idea of Sculpture. In Naum Gabo: The Constructive Idea, Sculpture, Drawings, Paintings, Monoprints, 41-51. London: South Bank Centre Exhibition Catalogue.

Hammer, Martin, and Christina Lodder. 2000a. Constructing Modernity: The Art \& Career of Naum Gabo. New Haven, London: Yale University Press.

Hammer, Martin, and Christina Lodder. 2000b. Introduction. In Gabo on Gabo: Texts and Interviews, ed. Martin Hammer and Christina Lodder, 5-18. Sussex: Artists Bookworks.

Kemp, Martin. 1996. Doing What Comes Naturally: Morphogenesis and the Limits of the Genetic Code, Art Journal 55.1 (Spring): 27-32.

Kemp, Martin. 2006. Seen/Unseen: Art, Science, and Intuition from Leonardo to the Hubble Telescope. Oxford: Oxford University Press. 
Lockwood, E. 1961. Evolutes and Involutes. In A Book on Curves, 167-72. Cambridge:

Cambridge University Press.

Mattheck, and I. Tesari. 2004. Uniform Stress: A Design Rule for Biological Load Carriers. In Optimization Mechanics in Nature, ed. M.W. Collins, D.G. Hunt, and M.A.Atherton, 15-34. U.K: WIT Press.

Michell, A.G.M. 1904. The Limits of Economy of Material in Frame-Structures. Philosophical Magazine 8: 589-97.

Nash, Steven. 1985. Naum Gabo: Sculptures of Purity and Possibility. In Naum Gabo: Sixty Years of Constructivism, ed. Steven Nash and Jörn Merkert, 11-46. Munich, New York: PrestelVerlag.

Our Art Critic, 2000. Interview: Naum Gabo: 'Space is Not Outside Us'. In Gabo on Gabo: Texts and Interviews, ed. Martin Hammer and Christina Lodder, 241-3. Sussex: Artists Bookworks.

Pasini, Damiano. 2003. A New Theory for Modelling the Mass-efficiency of Material, Shape and Form. PhD thesis, Bristol University.

Pasini, D., and S. Burgess. 2004. The Structural Efficiency of Trees. In Optimization Mechanics in Nature, ed. M.W. Collins, D.G. Hunt and M.A. Atherton, 51-78. U.K: WIT Press.

Pasini D., S. C. Burgess and D.J. Smith. 2006. A Method for Selecting Macro-scale Structures with Axially loaded Members. International Journal of Mechanics and Materials in Design 3: 185-99.

Pasini D. 2007. Shape Transformers for Material and Shape Selection of Lightweight Beams. Journal of Materials and Design 28/7: 2071-79.

Read, Herbert. 1942a. The Universal Harmony. The Listener, August: 187.

Read, Herbert. 1942b. Vulgarity and Impotence: Speculations on the Present State of the Arts. Horizon 5.28 (April): 267-76.

Read, Herbert. 1966. Preface. In Aspects of Form, ed. Lancelot Law Whyte. Bloomington, London: Indiana University Press.

Thompson, D'Arcy Wentworth. 1917. On Growth and Form. Cambridge: Cambridge University Press.

Thompson, David. 2000. Naum Gabo Talks to David Thompson. In Gabo on Gabo: Texts and Interviews, ed. Martin Hammer and Christina Lodder, 276-82. Sussex: Artists Bookworks. 
Yates, Robert. 1952. Evolutes, Involutes. In A Handbook on Curves and Their Properties, ed. Ann Arbor and J.W. Edwards, 86-91, 135-7. Washington: National Council of Teachers of Mathematics. 